\title{
Motion sensor technologies in education
}

\author{
T. Bratitsis ${ }^{1, *}$, M. Kandroudi ${ }^{2}$ \\ ${ }^{1}$ University of Western Macedonia, $3^{\text {rd }} \mathrm{km}$ National Road Florinas Nikis, Florina 53100, Greece \\ ${ }^{2}$ University of Western Macedonia, $3^{\text {rd }} \mathrm{km}$ National Road Florinas Nikis, Florina 53100, Greece
}

\section{Abstract}

This paper attempts to raise a discussion regarding motion sensor technologies, mainly seen as peripherals of contemporary video game consoles, by examining their exploitation within educational context. An overview of the existing literature is presented, while attempting to categorize the educational approaches which involve motion sensor technologies, in two parts. The first one concerns the education of people with special needs. The utilization of motion sensor technologies, incorporated by game consoles, in the education of such people is examined. The second one refers to various educational approaches in regular education, under which not so many research approaches, but many teaching ideas can be found. The aim of the paper is to serve as a reference point for every individual/group, willing to explore the Sensor-Based Games Based Learning (SBGBL) research area, by providing a complete and structured literature review.

Keywords: Kinect, Wii, PlayStation, Games Based Learning, Special Needs Education, categorization

Received on 22 December 2013, accepted on 31 March 2014, published on 22 May 2014

Copyright ( 2014 T. Bratitsis and M. Kandroudi licensed to ICST. This is an open access article distributed under the terms of the Creative Commons Attribution licence (http://creativecommons.org/licenses/by/3.0/), which permits unlimited use, distribution and reproduction in any medium so long as the original work is properly cited.

doi: $10.4108 /$ sg.1.2.e6

\section{Introduction}

Nowadays, technology has expanded rapidly, covering many aspects of everyday life, such as game playing. The latter has evolved to a whole new era, as motion sensing technologies have been integrated in game consoles, allowing more realistic and immersive gameplay. This paper will attempt to examine the exploitation of such technologies in console games for educational purposes. Motion sensors are devices which provide a natural user interface, allowing users to interact without any intermediary device. They can capture gestures and/or detect voice

Motion sensing is a technology which emerged widely in the market within the past 5-7 years. Nevertheless, several research approaches can be found in the literature, exploiting this technology within educational settings. This paper aims at enumerating these approaches, while categorizing them using multiple perspectives. The latter vary from level of education, to types of education (namely common or special education), or even cognitive areas (e.g. mathematics, physics, etc.). Furthermore, the significance of sensor technologies for education is highlighted through a brief review of the existing

*Corresponding author. Email:bratitsis@uowm.gr technologies of this kind, already integrated in educational contexts.

This paper will present a literature review, while attempting to categorize the educational approaches which involve motion sensor technologies. The aim of the present study is to provide a complete and structured literature review which can be used as a reference point for every individual group willing to explore the sensor-based GBL research area. Additionally, the paper will attempt to raise a discussion on how these technologies can be further exploited, taking into account that free tools (e.g. Scratch programming platform and Kodu programming language) are available for educators, enabling them to integrate motion sensors in educational activities. Some indicative examples will be provided, thus raising open research questions, building upon an existing classification attempt of commercial Microsoft Xbox Kinect games (Kandroudi and Bratitsis, 2012).

The paper is structured as follows; initially the theoretical background is established. Afterwards, the most common sensing technologies for video game consoles are briefly presented. Then a brief description of sensor technologies which have already been successfully integrated in education is presented. Finally, a review of 
the existing literature, divided in approaches for the special needs education and for the regular education is made, before the concluding discussion.

\section{Theoretical Background}

Playing can be a powerful learning approach, through which students could develop new skills and participate in new social environments, undertaking new social roles (Vygotsky, 1978). Playing games is quite different from the way students learn in school. Gee (2003), argues that games allow players to be knowledge producers rather than in the school scenario where students too often consume but do not produce. Playing games requires deep thinking (Squire, 2008) and it is crucial for learning since students take part in active experiences and not simply receive information, passively (Whitton \& Moseley, 2012). Researchers (Parsons et al., 2000; Charitos \& Martakos, 2000) support that through Virtual Environments users can practice skills safely, avoiding potentially dangerous real world consequences. For instance, users with special needs (e.g. children with autism spectrum disorders) could practice social skills, while reducing the impact of a possible social failure. Moreover, sensor based technology could enhance their abilities and help them to cultivate their skills by putting them in situations in which probably they couldn't respond to in real life.

Games' virtual worlds are powerful by making it possible to develop situated understanding, effective social practices, powerful identities, and shared values (Shaffer et al., 2004). Additionally, they can support the development of logical thinking and problem solving skills (Inkpen et al., 1995; Higgins, 2000). Computer and video games could be used as an innovative tool for constructive teaching approaches in classrooms. Constructivism states that people construct their own understanding and knowledge of the world, through realistic activities which allow them to gain experiences and reflection upon those experiences (Vygotsky, 1978).

MacFarland et al. (2002), based on how learning is achieved distinguish games in those which: a) learning is achieved as a result of tasks stimulated by the games' content, b) knowledge is developed through the game content, and c) skills arise as a result of playing the game. It seems that the educational use of the games depends on the teacher's creativity. Kandroudi \& Bratitsis (2012) support that games could not teach anything on their own; the educator is responsible for finding creative ways of incorporating the simulated worlds of the games into exciting learning activities. Furthermore, MacFarland et al. (2002) indicate the crucial relationship between games and the associated learning, which teachers should take into consideration. Oblinger (2006) states that pupils should be involved, through technology, in the learning process to: a) be engaged with the theories, b) acquire knowledge through autonomous and discovery learning, c) cultivate thinking skills, d) learn how to learn (metacognition), e) interact and communicate, and f) operate as active knowledge producers.

\section{Motion sensor technology}

Several sensing technologies can be found in the computer and console games market. Currently, three of them stand out, based on their market share and their innovative functionalities. These are: a) Nintendo Wii, b) Microsoft Kinect, and c) Sony PlayStation Move.

The Nintendo Wii incorporates the Wii-remote controller (Figure 1a), a handheld device which can be utilized as a gesture recognition and pointing tool. Its main technology is an infrared led, combined with an infrared sensor, built-in the console which allows the spatial detection of the controller. Thus, mimicking of actual game actions, such as swinging a racket, a sword or manipulating a fishing pole can be achieved by the user. Furthermore, the controller incorporates an accelometer for detecting rotation in all three axes, allowing more sophisticated and verisimilar gestures. Up to four WiiRemote controllers can be connected simultaneously using Bluetooth technology. The Wii-Remote Plus also includes a speaker, a rumble feature and an expansion port. Several add-ons have been designed for the Wii Remote controller by various manufacturers, allowing a more realistic integration of the end user to the game environment. Such examples are the Wii Wheel for driving, the Wii Zapper which imitates a weapon or even add-ons that turn the Wii Remote into a fishing pole, a snooker cue and other interesting appliances. With a broadband Internet connection, Wii can communicate with the Internet. The WiiConnect $24^{\mathrm{TM}}$ service delivers updates and content even if the system is turned off.

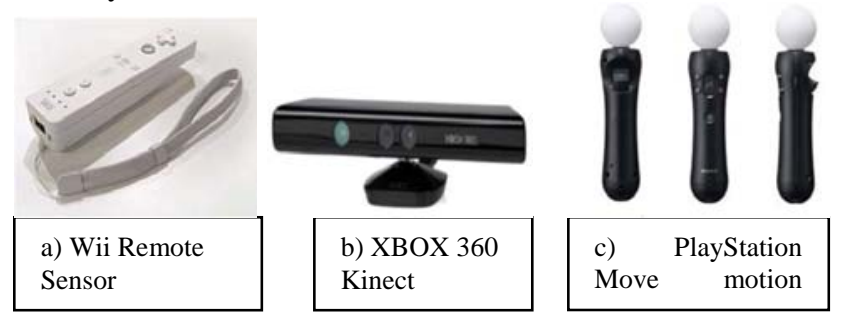

Figure 1: Motor sensors for video consoles

Kinect is a motion sensing input device for the Microsoft Xbox 360 console. It provides a natural user interface, allowing user interaction without any intermediary device. It is a horizontal bar connected to a motorized pivot base, designed to be positioned lengthwise above or below the video display (Figure 1b). It features an RGB camera, an infrared depth sensor and a multi-array microphone running proprietary software, which provides full-body 3D motion capture, facial recognition and voice recognition capabilities. Kinect identifies individual players through face, body and voice recognition, allowing the most realistic immersion of a user in the game environment, as the user's body is the actual gaming device. Moreover, the sensor can be used as an input device for Windows based computer systems. The Kinect 
sensor introduces two innovative characteristics: a) motion sensing which captures gestures and voice, and b) Xbox LiVE. The former has the potential to enhance kinesthetic learning and the latter the potential to increase the online interaction and communication among users (Kandroudi \& Bratitsis 2012).

A new version of the Kinect sensor has been recently released, featuring better performance, but also the ability to track up to 6 persons at once and to "see in the dark" through infrared technology. It can also detect a player's heart rate, facial expression, 25 individual joints (even thumbs) and the precise rotation of such joints, the weight put on each limb, and the speed of the player's movements, and track gestures performed with a standard controller.

PlayStation Move is a motion-sensing game controller platform for the PlayStation 3 (PS3) game console. Built around a handheld motion controller wand (Figure 1c), using the PlayStation Eye- camera to track its position, and inertial sensors in the wand to detect its motion. The wand features an orb which can glow, using RGB LEDs. Based on the environment's colors the system dynamically selects an orb color that can be distinguished from the rest of the scene. The colored light serves as a known size and shape active marker, the position of which can be tracked along the image plane by the camera in three dimensions, with high precision and accuracy. A pair of inertial sensors inside the controller, a 3axis linear accelerometer and a 3-axis angular rate sensor, are used to track rotation and overall motion. An internal magnetometer is also used for calibrating the controller's orientation against the Earth's magnetic field to help correct against cumulative error (drift) by the inertial sensors. In addition, an internal temperature sensor is used to adjust the inertial sensor readings against temperature effects. The inertial sensors can be used for dead reckoning in cases which the camera tracking is insufficient, such as when the controller is obscured behind the player's back.

\subsection{Other sensing technologies with educational use}

Nowadays, several sensing technologies exist, some of which are widely exploited in educational contexts. Some of them are briefly presented thereinafter. Although this paper focuses on motor and full body sensors, this chapter highlights the interconnection of the educational community with sensor based technologies.

The Scratch Sensor Board (Figure 2a), also referred to as ScratchBoard is an external electronic board which is connected to a Scratch (http://scratch.mit.edu/) running computer via USB. It incorporates four electric circuit resistor sensors (A to D), a button, a sound sensor, a light sensor and a slider. These provide the Scratch programming interface with numerical values which can be exploited, allowing the user to physically interact with Scratch applications. Scratch is a programming language, originally built for teaching computer programming to young children. The simplicity of the interface and the huge online community which supports
Scratch has allowed its wide adoption by the educational community, worldwide.
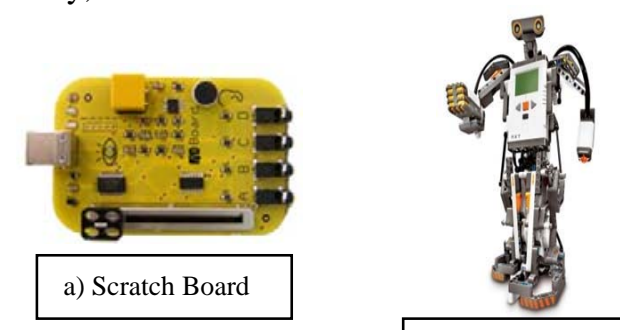

b) Lego robot
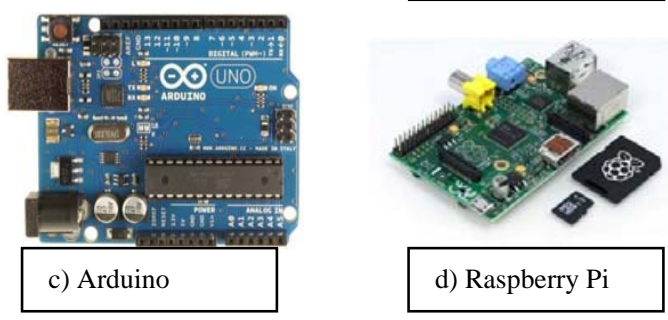

d) Raspberry Pi

\section{Figure 2: Other computer related sensor technologies}

Two teaching modules, based on the combination of Scratchboard and Scratch, to be used for the study of materials' thermal properties such as thermal conductivity and heat capacity was developed by Pierratos et al. (2009). Zigelbaum et al. (2006) presented the BodyBeats Suite in which three prototypes were built to explore the interaction between children and computational musical instruments by using sound and music patterns. Also, Louki \& Bratitsis (2011) exploited the ScratchBoard for implementing with a custom made stepping-mat, in order to examine spatial orientation issues regarding Kindergarteners ad facilitate cognitive conflicts on that matter.

In fact, the Scratch environment has been recently upgraded to version 2.0, which incorporates user physical interaction through a simple web camera, thus following the trend of sophisticated (full body) motion sensing in order to allow physical interaction of the user with the computer application.

The Lego Mindstorms series kits contain software and hardware which allow the creation of small, customizable and programmable robots. They include a programmable brick computer that controls the system, a set of modular sensors and motors, and Lego parts from the Technics line to create mechanical systems. The variety of available sensors is quite big, including color, sound, infrared, touch, ultrasonic and other sensors. These allow the programmable robotic constructions (Figure 2b) to interact with the physical environment. Two categories of Lego kits are available: Lego WeDo for Primary Education and Lego NXT for Secondary and Higher Education.

It is apparent that the educational community has embraced the Lego kits, from the large amount of related scientific papers available in the literature. Klassner \& 
Anderson (2003) studied the possibility of using the Lego Mindstorms robots to support the ACM Computing Curriculum 2001, using them in lab exercises and projects for classes from beginning courses in programming to advanced courses in operating systems, compilers, networks and artificial intelligence. Barnes (2002) argues about the use of Lego Mindstorms kits in various computing courses. Specifically he explored the Lego Mindstorms models using Java within the context of an introductory programming course.

Arduino (Figure 2c) is a single-board programmable microcontroller which can be connected with external electronic circuits, allowing the construction of complex, robotic-like devices. It is connected via USB to a computer in order to upload custom applications to be executed by the microcontroller. It is accompanied by a programming language for that matter, resembling $\mathrm{C}++$ code. During the past year, more user friendly programming interfaces have been deployed, such as the Scratch4Arduino (http://s4a.cat/) environment. The main advantage of the Arduino board is its low cost and the fact that it is distributed under the Creative Commons License. On the other hand, some basic knowledge and skills on electronics and the construction of circuits is required in order to create artefacts. Arduino comes in the form of various kits which allow the novice user to construct simple circuits and devices, but also a vast number of add-ons, referred to as shields, is available, allowing the easier manipulation of the Arduino board and the construction of external sensors. The latter allow the interaction of Arduinobased robotic construction with the physical environment.

Despite the complexity of Arduino, it is already used in education. Programming activities with the use of Scratch and S4A have been developed by first year students of a technical institute, during the school year 2010-2011. The experience gained is a suitable reference activity for a new Informatics curriculum in technical schools as also to all types of secondary schools when integrated with other components (Barbero et al., 2011).

Recently, other similar devices, such as the Raspberry $\mathrm{Pi}$ (Figure 2d) have been deployed and gaining momentum in education, mainly for science related courses, in all levels of education.

\section{Literature review}

In the previous section, the significance of games in the learning process and the arising interest in motion sensor technologies was established. This paper attempts to categorize the educational approaches which involve such technologies. A literature review was implemented during the first trimester of 2013, involving the ECGBL and the major ICT related international conferences of the past 6 years, resulting to about 100 papers. Also, keyword-based search was conducted, using combinations of the following terms: XBOX Kinect, Nintendo Wii, Sony PlayStation, sensor based learning, games based learning, virtual worlds special needs education, Kinect education. This search was applied in electronic databases and content specific websites (Google
Scholar, Scopus, Elsevier, Springer, Schoolnet (http://www.eun.org/), ERIC, IEEE xplore, Kinecteducation (http://www.kinecteducation.com/), Mendeley). Finally, the same keywords were used for surveying through the Google search engine. Repetitions of ideas and cross-references were omitted, leading to subset of articles, from which the ones considered as more innovative and/or important were selected, to be presented further bellow. The readers are reminded that this paper focuses mainly on motion and full body sensor technologies.

\subsection{Special needs education}

\subsubsection{Deaf education and sign language}

Aimaiti \& Yan (2011) argue about gesture based interaction, provided by the XBOX Kinect sensor. They support that XBOX Kinect could be a powerful tool for computers to understand human body language, thus providing opportunities in sign language training or medical research. In accordance with this claim, Lang et al. (2012) exploited Kinect for supporting sign language learning. According to them, Kinect offers 3D data in a simple camera setup from which information regarding the users' body parts can be distinguished and extracted. The latter, allows easier recognition of not just hands and head, but also other body parts, such as elbows, which can further facilitate the distinction of a variety of language signs. They also highlight the independency of lighting conditions, due to the use of infrared light by Kinect (Lang et al., 2012).

Moreover, Pyfers (2012) argues that Kinect could be a useful asset for educating deaf people. She indicates that Kinect may finally enable sign recognition applications to reach real users in real life settings. Furthermore, Zafrulla et al. (2011) while investigating the potential of the Kinect camera for sign language recognition, they support that this sensor could be a viable option for sign verification.

\subsubsection{Autism and Down Syndrome}

Hsu (2011) refers to a research conducted at Nottingham Trent University by Rachael Folds, who examined the effect of the Nintendo Wii and Xbox Kinect in helping college students with learning difficulties. The research population comprised of 16 to 24 years old students with disabilities, ranging from Down's Syndrome to autism spectrum disorders. They were asked to play tennis using a Wii game and bowling using a Kinect game. The results indicate that with five weeks of computer game training, two groups of participants significantly improved their motor skills, comparing the pre- and post- test scores, in realistic activities (Hsu, 2011).

Wuang et al. (2011) indicated that the Wii console virtual environment improved the motor proficiency, the visual-integrative abilities, and the sensory integrative functions in children with Down's Syndrome, from 7 to 12 years old. Specifically, comparing control and study groups the post- intervention results of MANOVA tests 
revealed a significant overall group effect. Rahman (2010), by examining the effectiveness of Nintendo Wii Fit balance games supports that as a virtual reality-based therapy, it could improve the balance of children with Down Syndrome, from 10 to 13 years old. In particular, he compared the post-Wii intervention mean values of balance for the control group and the study group by using the independent samples t-test, revealing a highly significant difference. The Lakeside Center for Autism integrates Kinect's full body play technology into its therapy sessions, for assisting children with autism to overcome various difficulties regarding physical and social development. For instance, they use commercial games, such as Kinect Adventures and Kinect Sports, to improve motor skills. They refer that autistic children accomplished all the activities and the only problem was the partial loss of calibration when a child went outside the system's focal area. Kee (2009) implemented a case study with the participation of autistic children, involving car racing video games for learning physics, on the PlayStation 3 console. He supports that racing video games provide a learning framework for building the sense of physics. In compliance to him, Li et al. (2012) support that a webcam motion sensor game has effective results in autistic students' training.

\subsubsection{Other disabilities}

Hammond et al. (2013) suggest that the Wii Fit game can be used to improve the motor skills of children with Developmental Co-ordination Disorder. Moreover, they argue about exploiting Wii Fit within a therapeutic programme for children with movement difficulties. Shih et al. (2010) studied two children with multiple disabilities, while using the Nintendo Wii Balance Board. They support that the device helped them to adjust their abnormal standing posture. Butler \& Willet (2010) discuss the benefits of the Wii Balance Board for patients' rehabilitation, regarding gross motor coordination, balance and strength. The Wii Balance Board is a Bluetooth input device bundled with the Wii Fit It implements the same protocol as the Wii Remote for hosting communications, and exposes most of its functionality via an extension controller. Most of the basic activities involving the Wii Balance Board are carried out using the positions shown in Figure 3. There may be other types of activities depending on the type of game being played, usually provided by the game manual.

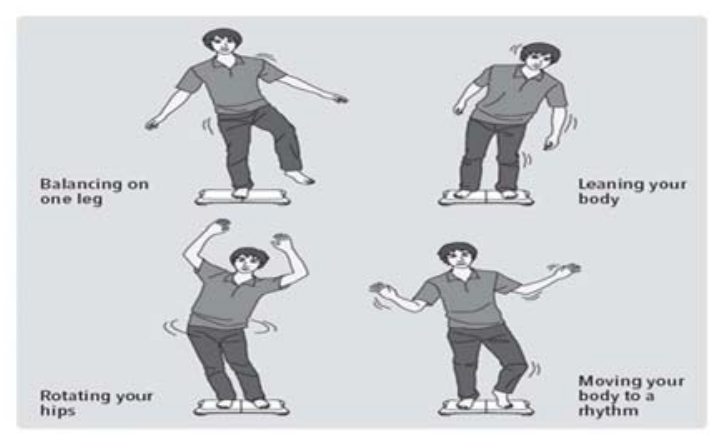

Figure 3: Wii Balance Board
Table 1: Categorization of motion sensor utilization in the education of people with special needs.

\begin{tabular}{|c|c|c|}
\hline Authors & Console & Study/ Results \\
\hline $\begin{array}{l}\text { Lang et al., } \\
2012\end{array}$ & $\begin{array}{l}\text { XBOX } \\
\text { Kinect }\end{array}$ & $\begin{array}{l}\text { Kinect for supporting sign } \\
\text { language learning. }\end{array}$ \\
\hline $\begin{array}{l}\text { Aimaiti \& } \\
\text { Yan,2011 }\end{array}$ & $\begin{array}{l}\text { XBOX } \\
\text { Kinect }\end{array}$ & $\begin{array}{l}\text { Powerful tool for computers in } \\
\text { order to understand human } \\
\text { body language and thus } \\
\text { providing opportunities in sign } \\
\text { language or medical research. }\end{array}$ \\
\hline $\begin{array}{l}\text { Butler \& } \\
\text { Willet,2010 }\end{array}$ & Wii & $\begin{array}{l}\text { Benefits of Wii Balance Board } \\
\text { in patients' rehabilitation } \\
\text { regarding gross motor co- } \\
\text { ordination, balance and } \\
\text { strength. }\end{array}$ \\
\hline $\begin{array}{l}\text { DePriest } \\
\text { \&Barilovits, } \\
2011\end{array}$ & $\begin{array}{l}\text { XBOX } \\
\text { Kinect }\end{array}$ & $\begin{array}{l}\text { Valuable applications for } \\
\text { physical therapy and home } \\
\text { rehabilitation exercises. }\end{array}$ \\
\hline $\begin{array}{l}\text { Hammond } \\
\text { et al.,2013 }\end{array}$ & Wii & $\begin{array}{l}\text { Effectiveness in motor skills of } \\
\text { children with Developmental } \\
\text { Co-ordination disorder. }\end{array}$ \\
\hline
\end{tabular}

Kee, 2009 PlayStation Case study research with Move autistic children regarding racing car video games for learning physics.

Pyfers,2012 XBOX Kinect technology could be a Kinect useful asset for educating deaf people.

Rahman, Wii Balance improvement for $2010 \quad$ children with Down syndrome.

Shih et al., Wii Nintendo Wii Balance Board 2010 on two children with multiple disabilities helped them to adjust their abnormal standing posture.

Urturi et $\quad \mathrm{XBOX} \quad$ Exploitation of XBOX Kinect al.,2012 Kinect for disabled people, in wheel chairs indicated an increase in their motivation although the game concerned physical exercises.

Wuang et Wii Wii virtual reality improved al.,2011 motor proficiency, visualintegrative abilities, and sensory integrative functions in children with Down Syndrome.

Zafrulla et XBOX Kinect can be a viable option for al.,2011 Kinect sign verification.

Urturi et al. (2012) conducted a research study which exploited XBOX Kinect for training disabled people, permanently attached to wheel chairs. Their findings indicate an increase in users' motivation although the game concerned physical exercises. Furthermore, the motion tracking abilities of Xbox Kinect seem to provide 
the opportunity of the implementation of valuable applications for physical therapy and home rehabilitation exercises. Doctors and patients connected through Xbox Live carried out prescribed rehabilitation courses which were graded and assessed (DePriest \& Barilovits, 2011). Patients who have suffered a stroke and other brain injury at the Royal Berkshire Hospital are promoting Kinect as an important part of their rehabilitation process. Canton et al. (2012) highlight the difficulties which people with motor disabilities face when using the computer mouse. They believe that gesture based devices could help children with learning or developmental disabilities to understand that using a hand gesture could be used instead, for pointing at digital artifacts.

In this section, the utilization of motion sensor technologies, in the education of people with special needs was examined. Table 1 presents a classified overview of the corresponding approaches.

\subsection{Motion sensor technology in regular education}

In this section, the exploitation of motion sensor technologies in regular education is examined. Microsoft wished to test the hypothesis that the language skills of primary school students can improve through exposure to English, as a foreign language, while playing games using the Xbox console with Kinect technology (Lisle, 2012). A pilot case study was implemented for one year in Lakeside Park Primary School, in rural KwaZulu-Natal, South Africa. Two classes from each one of grades 1 to 3, with an average class size of 42 learners and 6 teachers participated the study. An overall marked improvement in vocabulary which in turn impacted on comprehension and overall literacy skills was observed. The researchers also documented an increase in general knowledge and an increased enthusiasm for learning (Schoolnet, 2012).

DePriest \& Barilovits (2011) outline two interesting learning opportunities via Xbox LIVE with Kinect, the Video Kinect and Avatar Kinect software. The important feature in these cases is that both can host synchronous or asynchronous conferences or classes and achieve high engagement, interaction and communication among users, for cultivating language proficiency.

Kirriemuir (2002) argues about the benefits of game use in classroom. He supports that a group exercise using a video game in classroom could continue at home as homework. This homework could be emailed to the teacher when the game completed. In addition, he indicates the possibilities for console based teaching and learning in case of relevant software. For instance, the user could manipulate genetic material, combine chemicals, understand physics rules, engaged with political and civilization skills. Moreover, Kirriemuir \& McFarlane (2003) indicate five main scenarios in which games are used in classrooms: 1) Games in schools as research projects, 2) Games in school- oriented competitions, 3) Games used in computer labs, 4) Games as a vehicle for literacy or critique, and 5) Games as a reward for good behaviours.
Lee et al. (2012) created an interactive, gesture controlled arithmetic Kinect math game, called Xdigit. It was created to help students with math learning difficulties, incorporating various levels of difficulties to increase arithmetic complexity. It has not yet been evaluated within a research approach. Angotti and Bayo (2012) used Kinect with a group of teachers who volunteered to test it, for supporting math lessons. The implementation of the courses was successful and the teachers built a positive attitude towards the use of such tools in their classroom. After the completion of the project, the teachers reflected upon the study and indicated that the use of video games into the classroom should reevaluate the following: 1) classroom norms, 2) learning culture, 3) curriculum design, 4) implementation practices, and 5) post lesson reflection.

Wu et al. (2012) developed several interactive motion controlled games, utilizing Kinect, addressed to 5-8 year old students, to enhance learning. They indicate that the result of learning depends on the children's engagement with the game. Their study argues about the importance of integrating motion sensor technology into the classroom. Lien et al. (2012) studied the production of video portfolios in the classroom, allowing students to use their whole body, which was captured by Kinect and presented in a rich and context-sensitive background. Students could review their own performance under their teachers' guidance or alone to enhance their cognition or metacognition. The study results indicated that this approach could significantly enhance students' metacognition on Reflective, Sensing and Sequential learning styles.

Although several studies exist regarding the education of people with special needs, not many exist in regard to regular education. On the contrary, in the case of regular education, one can find many teaching ideas, mainly exploiting commercial games for the consoles under examination, but only a few research studies. As already mentioned, most of them are related to the Kinect sensor. Thus, for the rest of this section, an overview of the types of ideas, one can find across the internet. A logical classification of these ideas would follow the core constituents of almost every school curriculum, thus including the following categories: a) physical development, b) cognitive development, c) social development, and d) emotional development.

All three companies, namely Microsoft, Sony and Nintendo, have released games in the market, which they characterize as educational ones. For example, Sony has released the Little Big Planet 2Teacher Kit, which is a puzzle-platform game, centered on user generated content. The Kit features levels of the game which are themed around the USA National Curriculum subjects including physics, maths, science, art and history and is designed to help engage students in these subjects. For this matter, Sony has created ConnectEd, a company branch which focuses on the education sector. Nintendo has also released several titles which can be exploited for educational purposes. All the sports related titles can be 
utilized for physical development lessons, while all puzzle and problem based titles can be utilized for cognitive development. Regarding the emotional development, both companies have released titles which involve caring for something living (e.g. virtual pets), whereas social development is facilitated both by face to face and online collaborative playing.

The Greek Ministry of Education (2003), also states in the official Kindergarten's curriculum that the core educational goal is to facilitate the physical, emotional, cognitive and social development of children. Based on this classification, Kandroudi \& Bratitsis (2012) attempted to categorize the most popular Kinect games to help educators in exploiting them for teaching physical, cognitive, emotional and social skills. Table 2 summarizes the categorization of some of the most popular Kinect games, based on the four axes. This categorization complies with the discussion, initiated in the previous paragraph, regarding the other 2 technological platforms.

Table 2: Categorization of Kinect games' utilization for educational purposes in various developmental axes (Kandroudi \& Bratitsis, 2012).

\begin{tabular}{lcccc}
\hline \multicolumn{1}{c}{ GAME } & $\begin{array}{c}\text { Physical } \\
\text { develop- } \\
\text { ment }\end{array}$ & $\begin{array}{c}\text { Cognitive } \\
\text { develop- } \\
\text { ment }\end{array}$ & $\begin{array}{c}\text { Emotional } \\
\text { develop- } \\
\text { ment }\end{array}$ & $\begin{array}{c}\text { Social } \\
\text { develop- } \\
\text { ment }\end{array}$ \\
\hline $\begin{array}{l}\text { Body and brain } \\
\text { Connection }\end{array}$ & $\mathrm{X}$ & $\mathrm{X}$ & & \\
Kinect sports & $\mathrm{X}$ & & $\mathrm{X}$ & $\mathrm{X}$ \\
Kinectimals & & $\mathrm{X}$ & $\mathrm{X}$ \\
$\begin{array}{l}\text { The Fantastic } \\
\text { Pets }\end{array}$ & & $\mathrm{X}$ & $\mathrm{X}$ \\
$\begin{array}{l}\text { Kinect } \\
\text { Adventures }\end{array}$ & $\mathrm{X}$ & & $\mathrm{X}$ & $\mathrm{X}$ \\
$\begin{array}{l}\text { Disneyland } \\
\text { Adventures }\end{array}$ & $\mathrm{X}$ & & $\mathrm{X}$ & $\mathrm{X}$ \\
$\begin{array}{l}\text { Sesame street: } \\
\text { Once upon a } \\
\text { monster }\end{array}$ & & & & \\
Kinect FunLabs & & & & \\
\hline
\end{tabular}

\section{Conclusion}

This paper tried to present a literature review, while attempting to categorize the educational approaches which involve motion sensor technologies. This categorization consists of two parts. The first one concerns the education of people with special needs, under which many research approaches can be found. The second one refers to various educational approaches in regular education, under which not so many research approaches, but many teaching ideas can be found. As stated in the introduction of this paper, the intension of the authors was to categorize the existing approaches, based on the level of education they correspond to. The literature review reveals that almost all of the ideas and approaches regarding Games Based Learning are related to Primary (mainly) and Secondary Education. This was rather expected, considering that these ages are more interested in playing games in general. Moreover, much of the existing work in the Special Needs sector relates to rehabilitation or development of specific skills/dexterities. In this case, the ages span from minors to elderly people, but no classification related to level of education can be made, as the latter is rather relative to the situation and not the age of the students.

The main conclusion of this paper is that motion sensing technologies have been developed rapidly over the past years and many game titles are available, which seem to be exploited for educational purposes. One can find quite an amount of ideas and teaching material, although not always tested within the context of carefully designed research approaches. Nevertheless, the main characteristic of the digital age in which we live is that people create and share knowledge, information and ideas. Thus, many internet based communities are available, especially for educators willing to try innovative approaches. The innovative technologies have the potential to enhance the students' interest for knowledge and enlarge the educational motives. Since the young learners are considered as digital natives nowadays, it is crucial to capture their interest with technologically innovative ideas. As far as the latter is concerned, the motion sensing technology usage in education could transform a student to a young programmer who thinks, designs, evaluates, reflects and adjusts solutions. Moreover, motion sensor could enhance young students' motor skills and introduce new ways of problem solving skills development. It is obvious that the corresponding research has still a long way to go.

Another important issue, related to this discussion is the fact that some of the sensor technologies under examination are compatible with widespread educational tools. For example, the Kinect sensor can work with the Scratch (http://www.scratch.mit.edu/) programming environment, which incorporates a huge internet community and an equally large number of case studies. With Scratch as a mediation platform, Kinect can be combined with educational robotics (e.g. Lego WeDo set), thus providing new perspectives for educational researchers. It is also important to note that several sensor technologies are available, but this paper focused mainly on those which provide physical user experience in which the user freely uses his/her own body, with no particular space constrains. The latter is applicable, for example, in the case of the Wii Balance Board where the user is required to step only on the designated parts of the board. This facility is implemented in the recently introduced Kinect sensor of the XBOX one console by sophisticated algorithms which calculate the amount of pressure on each one of the legs of the user. Furthermore, it is important to 
explain the reason for focusing mainly on Kinect technology throughout this paper. The Software Development Kit of this sensor has been freely released and computer programmers have many tools for designing applications both on the XBOX console or a Windows based computer platform. Thus, more ad-hoc solutions oriented on the education sector, exploiting this technology, are available, whereas for the other famous motion sensing technologies the applications are mainly restricted to the exploitation of existing commercial games.

Overall, the motion sensing technology seems promising. Lately, several research approaches are surfacing within the educational research community. Many conferences related to ICTs and/or Education have started to include a Game Based Learning or even a Motion Sensor related section in their programmes, in 2013 and 2014. This indicates a research path being established, as the physical motion sensor technologies make the design of more immersive and realistic educational

\section{References}

[1] AIMAITI, N. \& YAN, X. (2011). Gestire-based Interaction and Implication for the Future. Umeå University.

[2] ANGOTTI, R. \& BAYO, I. (2012). Making Kinections: Using video game technology to teach math.

[3] BARBERO, A., DEMO, B., \& VASCHETTO, F. (2011) A contribution to the discussion on informatics and robotics in secondary schools. In Proceedings of 2nd international conference on Robotics in education, INNOC-Austrian Society for Innovative Computer Sciences.

[4] BARNES, D. J. (2002). Teaching introductory Java through LEGO MINDSTORMS models. ACM SIGCSE Bulletin (IGCSE'02). Covington, Kentucky, USA.

[5] BUTLER, D. P. \& WILLETT, K. (2010) Wii-habilitation: Is there a role in trauma? Injury 41(9): 883-885.

[6] CANTÓN, P., GONZÁLEZ, Á., MARISCAL, G. \& RUIZ, C. (2012) Applying new interaction paradigms to the education of children with special educational needs. Computers Helping People with Special Needs 65-72.

[7] CHARITOS, D., G. MARTAKOS. (2000). Employing virtual reality for aiding the organisation of autistic children behavior in everyday tasks. In: P. SHARKEY, A. C., L PUGNETTI \& A RIZZO (ed.) 3rd ICDVRAT. Sardinia Italy.

[8] CHOI, B., JUNG, J., \& BAEK, Y. (2013) In what way can technology enhance student learning?: A preliminary study of Technology Supported learning in Mathematics. In Proceedings of Society for Information Technology \& Teacher Education International Conference 2013, 3-9.

[9] DEPRIEST, D. BARILOVITS, K. (2011). LIVE: Xbox Kinect@s Virtual Realities to Learning Games. In Proceedings of TCC - Teaching Colleges and Community Worldwide Online Conference 2011, 48-54.

[10] EDUCATION, G. M. O. (2003). "A cross thematic curriculum framework for compulsory education”. In: EDUCATION, G. M. O. (ed.). Athens.

[11] GEE, J. P. (2003) What video games have to teach us about learning and literacy. Computers in Entertainment (CIE) 1(1): 20-20

[12] HAMMOND, J., JONES, V., HILL, E. L., GREEN, D. \& MALE, I. (2013) An investigation of the impact of regular use of the Wii Fit to improve motor and psychosocial activities possible. Thus, the main axis of the constructivistic and post-constructivistic theories, that of providing meaningful, real context situations and problems in order to achieve effective and high quality knowledge construction seems easier to be served.

Additional research is required, but actually it is obvious that it is already ongoing, to establish a concrete research basis, regarding the educational exploitation of these technologies. This paper attempted to raise the corresponding discussion and serve as a point of reference for any interested researcher, academic or students, by summarizing the core of the existing literature and providing an overview at a glance. Finally, by presenting a collective volume of literature, it can be exploited for further, future literature search, based on the existing research approaches.

outcomes in children with movement difficulties: a pilot study. Child: Care, Health and Development n/a-n/a.

[13] HIGGINS, S. (2000). The logical zoombinis. Teaching Thinking, 1(1): 12-14

[14] HSU, H.-M. J. (2011) The Potential of Kinect as Interactive Educational Technology. In Proceedings of 2nd International Conference on Education and Management Technology, 334-338.

[15] INKPEN, K.M., BOOTH, K.S., GRIBBLE, S.D., and KLAWE, M.M. (1995). Give and take: children collaborating on one computer. In J.M. Bowers and S.D. Benford (eds), CHI 95: Human Factors in Computing Systems, 258-259.

[16] KANDROUDI, M. \& BRATITSIS, T. (2012) Exploring the Educational Perspectives of XBOX Kinect Based Video Games. Proc. ECGBL 2012 219-227.

[17] KEE, N. K. N. (2009). Harnessing commercial off the shelf (COTS) video games in special education: A retrospective reflection of pedagogy and learning observed with three autistic children in game play. Learn to Game, Game to Learn" International Simulation and Gaming Association 40th Annual Conference. Singapore The International Simulation and Gaming Association.

[18] KIRRIEMUIR, J. (2002) Video gaming, education and digital learning technologies. D-lib Magazine 8(2): 25-32.

[19] KIRRIEMUIR, J. \& MCFARLANE, A. (2003). Use of computer and video games in the classroom. Level Up.

[20] KLASSNER, F., \& ANDERSON, S. D. (2003). Lego MindStorms: Not just for K-12 anymore. Robotics \& Automation Magazine, IEEE, 10(2), 12-18.

[21] LANG, S., BLOCK, M. \& ROJAS, R. (2012) Sign Language Recognition Using Kinect. In: RUTKOWSKI, L., KORYTKOWSKI, M., SCHERER, R., TADEUSIEWICZ, R., ZADEH, L. \& ZURADA, J. (eds.) Artificial Intelligence and Soft Computing. Springer Berlin Heidelberg.

[22] LEE, E., LIU, X. \& ZHANG, X. (2012) Xdigit: An Arithmetic Kinect Game to Enhance Math Learning Experiences.

[23] LI, K.-H., LOU, S.-J., TSAI, H.-Y. \& SHIH, R.-C. (2012) The effects of applying Game-Based Learning to Webcam Motion Sensor games for autistic students' sensory integration training TOJET 11(4): 451-459

[24] LIEN, C.-L., HUANG, C.-Y., WANG, C.-Y. \& CHEN, G.-D. (2012) Using Kinect to Track Learning Behavior of Students in the Classroom as Video Portfolio to Enhance Reflection Learning. 
[25] LISLE P. (2012). Using the Xbox Kinect in Foundation Phase English Language Acquisition. Schoolnet

[26] MCFARLANE, A., SPARROWHAWK, A. \& HEALD, Y. (2002) Report on the educational use of games, Teachers evaluating educational multimedia).

[27] OBLINGER, D. (2006) Games and learning. Educause Quarterly Magazine 29(3): 5-7.

[28] PARSONS, S., BEARDON, L., NEALE, H., REYNARD, G., EASTGATE, R., WILSON, J.R. ET AL. (2000). Development of social skills amongst adults with Asperger's syndrome using virtual environments: The AS Interactive Project. In: P. SHARKEY, A. C., L. PUGNETTI, \& A. RIZZO (ed.) 3rd International Conference on Disability, Virtual Reality and Associated Technologies. Reading, UK: University of Reading.

[29] PIERRATOS, T., KOLTSAKIS, E., \& POLATOGLOU, H. M. (2009). Teaching materials' properties to K-12 students using a sensor board. MRS Proceedings, 1233.

[30] PYFERS, L. (2012). Sign 2.0: ICT for Sign Language Users: Information Sharing, Interoperability, UserCentered Design and Collaboration. In: MIESENBERGER, K., KARSHMER, A., PENAZ, P. \& ZAGLER, W. (eds.) Computers Helping People with Special Needs. Springer Berlin Heidelberg.

[31] RAHMAN, S. (2010) Efficacy of virtual reality-based therapy on balance in children with Down syndrome. World Applied Sciences Journal 10(3): 254-261.

[32] SCHOOLNET (2012). Schoolnet completes a study on the use of Xbox Kinect to improve literacy scores - interesting findings,[online],http://schoolnetsa.blogspot.gr/2012/03/sc hoolnet-completes-study- on-use-of.html

[33] SHAFFER, D.W., SQUIRE, K, HALVERSON, R. \& GEE, J.P. (2004). Video games and the future of learning, Phi Delta Kappan, 87(02):104-111

[34] SHIH, C.-H., SHIH, C.-T. \& CHU, C.-L. (2010) Assisting people with multiple disabilities actively correct abnormal standing posture with a Nintendo Wii Balance Board through controlling environmental stimulation. Research in Developmental Disabilities 31(4): 936-942.

[35] SQUIRE, K. D. (2008) Video games and education: Designing learning systems for an interactive age. Educational Technology 48(2): 17.

[36] URTURI, Z., MÉNDEZ ZORILLA, A. \& GARCÍA ZAPIRAIN, B. (2012). JeWheels: Kinect Based Serious Game Aimed at Wheelchair Users. In: BRAVO, J., HERVÁS, R. \& RODRÍGUEZ, M. (eds.) Ambient Assisted Living and Home Care. Springer Berlin Heidelberg.

[37] VYGOTSKY, L. (1978) Interaction between learning and development. Readings on the development of children 3441.

[38] WHITTON, N. \& MOSELEY, A. (2012) Using Games to Enhance Learning and Teaching: A Beginner's Guide, Routledge).

[39] WU, E.H., LIAO, C.W., HUANG, S., CHANG, C., CHEN, Z., YANG, J., LI, D. (2012). Kids Magic Learning: Kinect-based Game Learning Development and Practice. Taiwan Academic Network Conference

[40] WUANG, Y.-P., CHIANG, C.-S., SU, C.-Y. \& WANG, C.-C. (2011) Effectiveness of virtual reality using Wii gaming technology in children with Down syndrome. Research in Developmental Disabilities 32(1): 312-321.

[41] ZAFRULLA, Z., BRASHEAR, H., STARNER, T., HAMILTON, H. \& PRESTI, P. (2011) American sign language recognition with the kinect. In Proceedings of
Proceedings of the 13th international conference on multimodal interfaces, ACM), 279-286.

[42] ZIGELBAUM, J., MILLNER, A., DESAI, B., \& ISHII, H. (2006). BodyBeats: whole-body, musical interfaces for children. Proceedings CHI'06 extended abstracts on Human factors in computing systems, 1595-1600. 